\title{
Local Permutations in the Glomerular Array of the Mouse Olfactory Bulb
}

\author{
Jörg Strotmann, ${ }^{1,2}$ Sidonie Conzelmann, ${ }^{2}$ Anja Beck, ${ }^{2}$ Paul Feinstein,, ${ }^{1}$ Heinz Breer, ${ }^{2}$ and Peter Mombaerts ${ }^{1}$ \\ ${ }_{1}^{1}$ The Rockefeller University, New York, New York 10021, and 2/nstitute of Physiology, University Stuttgart-Hohenheim, \\ D-70593 Stuttgart, Germany
}

\begin{abstract}
Olfactory sensory neurons expressing a given odorant receptor gene project their axons with great precision to a few specific glomeruli in the olfactory bulb. It is not clear to which extent the positions of these glomeruli are fixed. We sought to evaluate the constancy of the glomerular array in the mouse by determining the relative positions of glomeruli for various odorant receptors, using a method that affords single-axon resolution, and in a large number of bulbs. We used a genetic strategy to visualize neuronal populations that express one of three members of the $m O R 37$ subfamily. We generated by gene targeting five strains of mice in which expression of a given mOR37 gene is linked to expression of an axonal maker, which is either taulacZ or tauGFP. The patterns of marker expression faithfully mimic those of the cognate receptors. Axons of neurons expressing a given mOR37
\end{abstract}

gene converge onto one or two glomeruli per bulb. Each mOR37 gene has its own glomeruli, and the mOR37 glomeruli are grouped within a restricted domain of the bulb. Serial sectioning of 214 bulbs reveals that the relative positions of the three types of glomeruli are not fixed but display local permutations. Importantly, this is also the case among the two bulbs from one individual, ruling out the genetic manipulation itself and differences in genetic background or olfactory experience as causes for the observed variability. These local permutations may reflect the developmental history of the glomeruli and are relevant for the construction of spatial odor maps.

Key words: olfaction; olfactory system; olfactory bulb; glomerulus; sensory neuron; olfactory receptor; odorant receptor
The vertebrate olfactory system detects and discriminates numerous chemical compounds. Odorant reception initiates when odorous molecules interact with specific odorant receptors (ORs) on the surface of olfactory sensory neurons (OSNs) (Shepherd, 1994). The OR repertoire is encoded by the largest gene family in the vertebrate genome, comprising as many as 1000 genes in mouse and rat (Buck and Axel, 1991) (for review, see Mombaerts, 1999a,b). Individual OSNs express a few OR genes, perhaps only a single one (Malnic et al., 1999). For most ORs, OSNs expressing a given OR are segregated within one of four zones of the olfactory epithelium in which they are interspersed with OSNs expressing other ORs (Ressler et al., 1993; Vassar et al., 1993; Strotmann et al., 1994). In contrast to their scattered distribution within an epithelial zone, OSNs expressing a given OR project their axons to a few common glomeruli in the olfactory bulb, as was revealed indirectly by in situ hybridization (Ressler et al., 1994; Vassar et al., 1994) and directly by axonal labeling (Mombaerts et al., 1996; Zheng et al., 2000). The latter approach is based on gene targeting in mice and results in $\beta$-galactosidase staining of the cell bodies, axons, and axon terminals of individual OSNs expressing a given OR. Using a similar genetic strategy, we provided evidence that ORs have instructive roles in directing axons to their appropriate glomeruli in the bulb (Mombaerts et al., 1996; Wang et al., 1998; Rodriguez et al., 1999). The concept of the glomerulus as a convergent site of axonal projections for OSNs expressing a given OR

\footnotetext{
Received March 30, 2000; revised June 20, 2000; accepted July 6, 2000.

This work was supported by the Deutsche Forschungsgemeinschaft Leibniz Programm, European Community Project TRANS ERBBIO4 4CT 960593, and the Fonds der Chemischen Industrie (all to J.S. and H.B.). P.F. was supported by postdoctoral fellowships from Bristol Myers Squibb and the National Institutes of Health. P.M. received grant support from the Human Frontier Science Program and the National Institutes of Health, and was an Alfred P. Sloan, Basil O'Connor, Guggenheim, Irma T. Hirschl, Klingenstein, McKnight, Rita Allen, and Searle Scholar or Fellow. We thank Annemarie Walsh, Susan Powell-Hayre, and Ruben Peraza of the Transgenic Service at The Rockefeller University for the efficient generation of chimeric mice. Chen Zheng is acknowledged for the IRES-tauGFP cassette, and Heiner Westphal for EIIa-Cre transgenic mice.

Correspondence should be addressed to Peter Mombaerts, The Rockefeller University, 1230 York Avenue, New York, NY 10021. E-mail: peter@mail.rockefeller.edu. Copyright (C) 2000 Society for Neuroscience $0270-6474 / 00 / 206927-12 \$ 15.00 / 0$
}

supports a model of olfactory coding in which odor quality is encoded by a specific combination of activated glomeruli (Mori et al., 1999).

Initial studies emphasized the stereotyped nature of the glomerular array of the bulb, a view that was based on analysis of the absolute positions of glomeruli corresponding to single ORs (Ressler et al., 1994; Vassar et al., 1994; Mombaerts et al., 1996; Wang et al., 1998). A recent report provides preliminary evidence for variability in the number and positions of the P2 glomeruli (Royal and Key, 1999), but the extent of this variability is less pronounced in other studies of the P2 OR (Costanzo, 2000; Lin et al., 2000; Zheng et al., 2000). The constancy of the glomerular array is best analyzed by determining the relative positions of glomeruli corresponding to various ORs, at single-axon resolution, and in a large number of bulbs. Such studies have yet to be performed.

Here, we have tagged three genes of the mOR37 subfamily by gene targeting in embryonic stem (ES) cells. The use of two histological axonal markers (Rodriguez et al., 1999) allowed us to perform double-labeling experiments for two distinct ORs. We demonstrate that axonal populations of OSNs expressing an mOR37 gene each project to one or two glomeruli per bulb. These glomeruli are grouped within a defined domain of the bulb, but their numbers and relative positions vary, even between both bulbs of the same mouse.

\section{MATERIALS AND METHODS}

Targeting vectors. Genomic clones containing $m O R 37$ genes were isolated from a 129/Sv mouse P1 genomic library (Genome Systems, St. Louis, MO). Fragments containing the respective OR37 coding regions were subcloned into pBS-SKII (Stratagene, La Jolla, CA). A PacI site was generated by recombinant PCR three nucleotides downstream of the stop codon of the $m O R 37 A, m O R 37 B$, and $m O R 37 C$ genes, respectively. A PmeI site was generated at the $3^{\prime}$ end of the targeting vectors for linearization of the construct. A PacI fragment containing IRES-taulacZ-LTNL (Mombaerts et al., 1996) was inserted into the PacI restriction site of $m O R 37 A$ and $m O R 37 C$, respectively. A PacI fragment containing IREStaulacZ-LNL (Rodriguez et al., 1999) was inserted into the PacI restriction site of $m O R 37 B$. A PacI fragment containing IRES-tauGFP-LNL (Rodriguez et al., 1999) was inserted into the PacI site of $m O R 37 A$ and $m O R 37 C$, respectively. The version of green fluorescent protein (GFP) used was EGFP-1 (Clontech, Palo Alto, CA). 
Gene targeting. Targeting vectors were linearized with PmeI. Electroporation and culture of E14 cells (Hooper et al., 1987) were performed as by Mombaerts et al. (1996). Genomic DNA from G418-resistant ES clones was digested with EcoRI and analyzed by Southern blot hybridization with a $5^{\prime}$ probe external to the targeting vector.

Targeted ES clones containing the $L T N L$ cassette were transiently transfected with the plasmid expressing the Cre recombinase. Genomic DNA from ganciclovir-resistant clones was digested with Eco RI and analyzed by Southern blot hybridization with a $3^{\prime}$ internal probe. Recombinant clones were injected into C57BL6/J blastocysts, and germ line transmission was obtained for $m O R 37 A-I T L Z$ (clone Y68/Cre8) and $m O R 37 C$ ITLZ (clone V37/Cre1).

Targeted ES clones containing the $L N L$ cassette were injected directly into blastocysts, and germ line transmission was obtained for $m O R 37 B$ ITLZ-LNL (clone B136), mOR37A-ITGFP-LNL (clone H26), and mOR37C-ITGFP-LNL (clone O44). The neo-selectable marker was subsequently removed by crossing mice heterozygous for the $L N L$ allele to EIIa-Cre transgenic mice (Lakso et al., 1996). Intercrosses of loxP-positive mice resulted in loxP-heterozygous and loxP-homozygous mice that were devoid of the Cre transgene. All analyses were performed with mice that did not carry the Cre transgene. Mice are in a mixed $(129 \times$ C57BL6/J $)$ background.

5-bromo-4-chloro-3-indolyl- $\beta$-D-galactopyranoside staining. Tissues were immersion-fixed in $2 \%$ paraformaldehyde in PBS, $\mathrm{pH} 7.4$, for $60 \mathrm{~min}$ at $8^{\circ} \mathrm{C}$, incubated in $25 \%$ sucrose overnight, and frozen in Tissue-Tek (Miles, Elkhart, IN). Twelve micrometer sections were cut on a Reichert \& Jung Frigocut 3000 and stained with 5-bromo-4-chloro-3-indolyl- $\beta$-D-galactopyranoside $(\mathrm{X}$-gal) as follows. They were washed with buffer A (100 mM phosphate buffer, pH 7.4, 2 mM $\mathrm{Mg}_{2} \mathrm{Cl}$, and $5 \mathrm{~mm}$ EGTA) once for $5 \mathrm{~min}$ and once for $25 \mathrm{~min}$ at room temperature, followed by two incubations of $5 \mathrm{~min}$ at room temperature in buffer B $(100 \mathrm{~mm}$ phosphate buffer, $\mathrm{pH} 7.4$, $2 \mathrm{mM} \mathrm{Mg}_{2} \mathrm{Cl} 0.01 \%$ sodium deoxycholate, and $0.02 \%$ Nonidet P-40). The blue precipitate was generated by exposure at $37^{\circ} \mathrm{C}$ to buffer $\mathrm{C}$ (buffer $\mathrm{B}$ with $5 \mathrm{~mm}$ potassium-ferricyanide, $5 \mathrm{~mm}$ potassium-ferrocyanide, and 1 $\mathrm{mg} / \mathrm{ml} \mathrm{X}$-gal).

Immunohistochemistry. Tissues were fixed for $45 \mathrm{~min}$ in $2 \%$ paraformaldehyde in $0.1 \mathrm{M}$ phosphate buffer, $\mathrm{pH} 7.4$, at $8^{\circ} \mathrm{C}$ and incubated in $25 \%$ sucrose overnight. Sixteen micrometer coronal sections were mounted on Superfrost slides (Fisher, Pittsburgh, PA). For $\beta$-galactosidase immunostaining, primary antibodies (Clontech) were used at a 1:500 dilution, followed by a 1:500 diluted goat anti-rabbit antibody conjugated to $\mathrm{Cy} 3$ (Jackson ImmunoResearch, West Grove, PA). Sections were mounted in Vectashield (Vector Laboratories, Burlingame, CA).

In situ hybridization on frozen sections. Templates for specific antisense RNA probes were generated by PCR amplification of the $3^{\prime}$ noncoding region. Amplification products were subcloned into the pGEM T-vector and sequenced before probe preparation.

$5^{\prime}$ primers were mOR37A/1, mOR37B/1, and mOR37C/1; $3^{\prime}$ primers were mOR37A/2, mOR37B/2, and mOR37C/2 (Strotmann et al., 1999). Probes were generated from templates using the SP6/T7 in vitro transcription system (Boehringer Mannheim, Basel, Switzerland). Two micrograms of linearized vector were transcribed in the presence of $70 \mathrm{nmol}$ of digoxigenin-11-uridine- $5^{\prime}$-trisphosphate. RNA was precipitated with ethanol and resuspended in $20 \mathrm{ml}$ of "in situ grade" hybridization buffer (Amersham Pharmacia Biotech, Piscataway, NJ) containing 50\% deionized formamide.

Mice were killed by $\mathrm{CO}_{2}$ asphyxiation and decapitated. The lower jaw and top of the skull were carefully removed using a bone cutter (Fine Science Tools, Foster City, CA). The tissue was embedded in Tissue-Tek and frozen on dry ice. Coronal sections of $10 \mu \mathrm{m}$ were cut on a cryostat at $-24^{\circ} \mathrm{C}$, adhered to Superfrost microslides, and air-dried for $2 \mathrm{hr}$. For in situ hybridization, tissue sections were covered with $10 \mu \mathrm{l}$ of hybridization solution containing $\sim 3-5 \mathrm{ng}$ of digoxigenin-labeled RNA and coverslipped. Hybridization and posthybridization washes were performed as by Strotmann et al. (1994).

Quantitative analyses. The relative positions of cell somata within the vertical dimension of the olfactory epithelium were determined as detailed previously (Strotmann et al., 1996) using a video camera connected to a Zeiss (Oberkochen, Germany) Axiophot microscope and the image analysis program Semper6 (Synoptics, Cambridge, UK). At 400× magnification, the vertical distance of a cell body from the basal membrane $(a)$ was determined. At the same position, the thickness of the cellular layer of the epithelium [the distance from the basal membrane to the nasal lumen $(b)$ ] was determined. The relative position of the cell soma was then determined as the quotient of $a$ divided by $b$.

Mice. The analyses were performed on a total of 214 bulbs from 129 different mice. The remaining 44 bulbs were judged uninformative, for instance, because of damage. For each genotype, 16-23 mice were analyzed from three to six litters. Both males and females were used at ages between 10 and 16 weeks.

Microscopy and photography. Whole-mount specimens were photographed using a Wild M8 stereomicroscope. Sections were analyzed with a Zeiss Axiophot microscope. Fluorescence was examined using the appropriate filter sets for $\mathrm{Cy} 3$ and EGFP. Overlay of fluorescent images was obtained by double or triple exposure of individual color slides (400 ASA). The fluorescent glomerulus was photographed in whole mount at $400 \times$ magnification using an Olympus Optical (Tokyo, Japan) IX70 inverted microscope with fluorescence optics.

\section{RESULTS}

\section{Targeted mutagenesis of mOR37 genes}

OSNs expressing ORs of the mOR37 subfamily occupy a circumscribed region within the epithelium that overlaps with three of the four expression zones for the other ORs (Strotmann et al., 1992; Kubick et al., 1997). In mouse, this subfamily comprises five highly related $m O R 37$ genes $(m O R 37 A-m O R 37 E)$ that are arranged in a cluster on chromosome 4; one sequence is a pseudogene (Strotmann et al., 1999). The genomic organization of the mOR37 gene cluster is summarized in Figure $1 A$. To construct targeting vectors, genomic clones encoding the $m O R 37 A, m O R 37 B$, or $m O R 37 C$ genes, respectively, were modified by insertion of a marker cassette $3^{\prime}$ of the stop codon. The cassettes were IRES-taulacZ, directing cotranslation of the OR together with taulacZ (henceforth referred to as $l a c Z$ ) (Mombaerts et al., 1996), or IRES-tauGFP (abbreviated as $G F P$ ) in which the lacZ coding sequence is substituted by that of the green fluorescent protein (Rodriguez et al., 1999). Five targeting vectors were designed for three $m O R 37$ genes (Fig. $1 B-D$ ), and five strains of gene-targeted mice were generated that carry the corresponding mutations. The neo-selectable marker was removed from the targeted mutations, because we have experienced that it frequently interferes with gene expression from targeted loci.

\section{Patterns of mOR37-expressing neurons}

We first confirmed that the spatial patterns of OSNs expressing the $m O R 37-l a c Z$ alleles match the patterns of OSNs expressing the corresponding wild-type alleles.

Whole-mount specimens of mice that carry either of the three $m O R 37-l a c Z$ mutations were stained with X-gal. Figure $2 A$ shows a view onto a half-head from a mouse homozygous for the mOR37A-lacZ (henceforth abbreviated A-lacZ) mutation. Bluecolored cell bodies are clustered in a patch in the center of the turbinates. This characteristic pattern also emerges when mice homozygous for the $m O R 37 B$-lacZ (B-lacZ) mutation (Fig. $2 B$ ) or the $m O R 37 C$-lac $Z$ (C-lacZ) mutation (Fig. $2 C)$ were stained. Whole-mount in situ hybridization using a digoxigenin-labeled riboprobe specific for $m O R 37 B$ labels cell bodies in a wild-type mouse (Fig. 2D) that are located in the same patch as those detected by X-gal staining of a $B$-lac $Z$ mouse (Fig. $2 B$ ). Similar results were obtained using $m O R 37 A$ - and $m O R 37 C$-specific probes (data not shown).

Coronal sections through the nasal cavity from a heterozygous $B$-lac $Z$ mouse (Fig. 2E) reveal the characteristic clustering of $\mathrm{X}$-gal-reactive OSNs expressing ORs from the $m O R 37$ subfamily on the tip regions of endoturbinates II and III and on ectoturbinate 3. In adjacent sections of the same specimen (Fig. $2 F$ ), in situ hybridization identifies cells expressing $m O R 37 B$ from the targeted or wild-type allele. Importantly, the spatial patterns of the cells reacting with X-gal histochemistry (Fig. $2 E$ ) or in situ hybridization (Fig. $2 F$ ) are superimposable; there are no areas that contain only cells reactive with the riboprobe (reflecting either the targeted or wild-type allele) but not with X-gal (representing the targeted allele). Similar results were obtained with $A$-lac $Z$ and $C$-lac $Z$ mice (data not shown). Thus, at a gross level, the spatial expression pattern of the $m O R 37$ genes is not affected by targeted insertion of the IRES-taulac $Z$ cassette.

\section{Laminar organization}

We have shown previously that, in mature ( $>6$-week-old) mice, OSNs expressing a particular OR gene exhibit an additional level of spatial organization within the olfactory epithelium; the cell bodies are arranged in distinct laminar layers (Strotmann et al., 1996). The significance of this phenomenon is not understood, but this layering provides the opportunity for another important control experiment regarding the regulation of expression of the targeted and wild-type alleles.

A cross-section through the epithelium of an $A$-lac $Z$ mouse after 

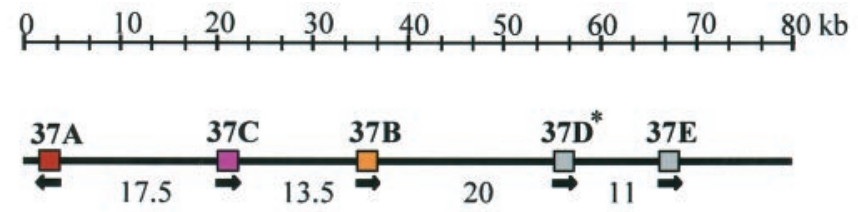

B

a)

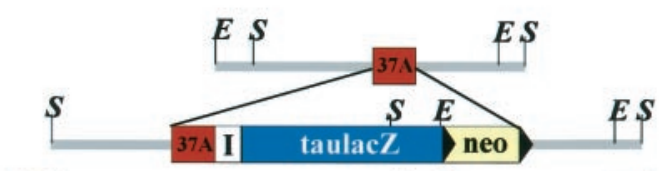

b)

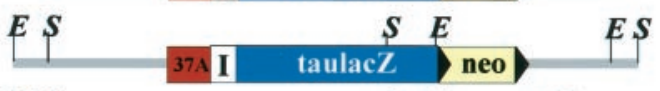

c)

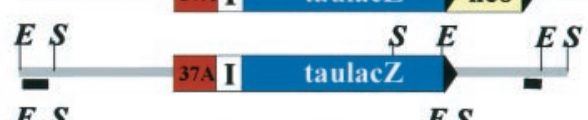

d)
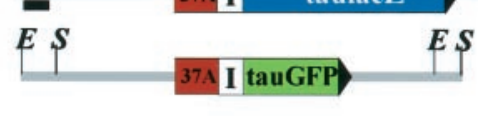

$\mathrm{C}$

e)

a)

)

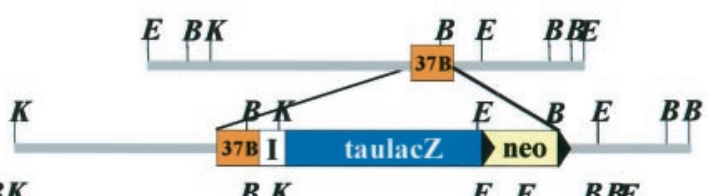

c)

$E$

B $\boldsymbol{K}$

taulacZ

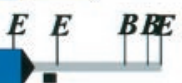

D

a)

b)

c)

d)

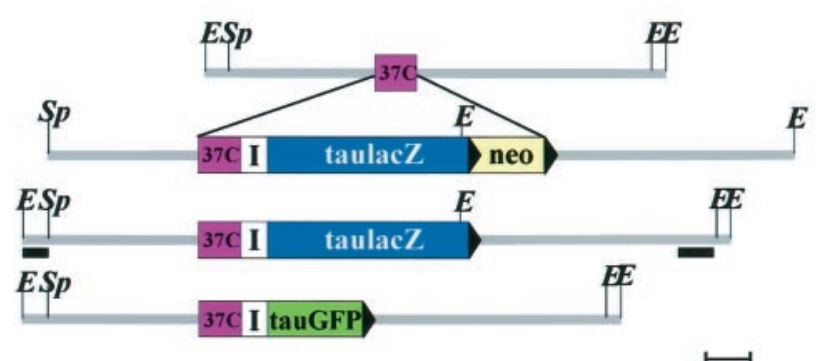

$\longmapsto$
Figure 1. Genetic strategy. A, Genomic organization of the mOR37 locus, redrawn from Strotmann et al. (1999). The coding regions are indicated by boxes (not drawn to scale), and their transcriptional orientation is indicated by arrows. The distance between the coding regions is given in kilobases. The asterisk indicates that $m O R 37 D$ is a pseudogene. $B-D$, Targeted mutagenesis of $m O R 37$ genes. $B$, mOR $37 A$. a, Wild-type mOR37A locus; the coding region is represented by a red box. Restriction sites are indicated for EcoRI $(E)$ and $S a c \mathrm{I}(S)$. $b, m O R 37 A$-IRES-taulacZ-LTNL targeting vector. The white box labeled $i$ represents the IRES sequence, the blue box represents the coding sequence of taulac $Z$, and the yellow box represents the neo-selectable marker LTNL (not drawn to scale) flanked by loxP sites (indicated by black triangles). $c$, mOR37A locus after homologous recombination. $d, m O R 37 A$ IRES-taulacZ (A-lacZ) mutation after Cre-mediated excision of the neo-cassette, which leaves a single loxP site behind. The $5^{\prime}$ and $3^{\prime}$ external probes used to detect, respectively, homologous recombination and $\mathrm{Cre}$ recombination, are indicated as horizontal bars on the left and right, respectively. e, mOR37A-IREStauGFP $(A-G F P)$ mutation, after Cre-recombination. $C$, $m O R 37 B$. $a$, Wild-type $m O R 37 B$ locus; the coding region is indicated by an orange box. Restriction sites for EcoRI $(E)$, BamHI $(B)$, and KpnI $(K)$ are indicated. $b$, mOR37B-IREStaulacZ-LNL targeting vector. The yellow box represents the neo-selectable marker $L N L$ (not drawn to scale) flanked by loxP sites (indicated by black triangles). c, mOR37B-IRES-taulacZ (B-lacZ) mutation after Cre-recombination. D, mOR37C. a, Wild-type $m O R 37 C$ locus; the coding region is indicated by a pink box. Restriction sites for EcoRI $(E)$ and SpeI (Sp) are indicated. $b, m O R 37 C$-IRES-taulacZ-LTNL targeting vector. $c$, mOR37C-IRES-taulacZ (C-lacZ) mutation, after Crerecombination. $d$, mOR37C-IRES-tauGFP $(C$-GFP $)$ mutation, after $C r e$-recombination.
X-gal staining is shown in Figure $3 A$. The dendrites and axons of individual $A$-lacZ expressing OSNs appear of similar length, implying that the cell bodies are preferentially located within the middle layer of the epithelium. The relative position within the cellular layer was determined quantitatively for a large number of A-lacZ-expressing OSNs (see Materials and Methods). Their cell bodies are predominantly located within the $0.4-0.6$ range (Fig. $3 B$ ), with few cells above and below these levels. The laminar preference of OSNs expressing the $M O R 37 A$ gene was confirmed in wild-type mice by in situ hybridization (Fig. $3 C$ ), with quantification of the results shown in Figure $3 B$.

Cell bodies expressing the $B$-lac $Z$ allele (Fig. $3 D$ ) are located closer to the luminal surface than $A$-lac $Z$ cells, within the range of $0.6-0.8$ (Fig. $3 E$ ). Cells expressing the $m O R 37 B$ wild-type allele exhibit a similar laminar patterning (Fig. $3 F$ ). Finally, OSNs expressing the $C$-lac $Z$ allele (Fig. $3 G$ ) have very short dendrites, because their cell bodies are situated even closer to the luminal surface than $m O R 37 B$-expressing OSNs, in a position $\sim 0.8-1.0$ (Fig. $3 H, I$ ). We note that the linear order of $m O R 37$ genes on the chromosome (A-C-B) does not correspond to the relative laminar positions within the epithelium (A-B-C), eliminating a simple correlation between these variables.

Thus, OSNs expressing a particular $m O R 37$ gene reside within distinct epithelial layers, and this configuration is replicated in the gene-targeted mice. We regard this observation as a sensitive indicator that the targeted insertion of IRES-taulacZ does not alter the pattern of gene expression in a major way.

\section{Mutually exclusive expression of mOR37 genes}

It is conceivable that $m O R 37$ genes are coexpressed in some OSNs. The availability of a second histological marker (tauGFP) allows us to examine this issue at the single-cell level. Double-heterozygous mice were generated that carry two differentially tagged mOR37 alleles; expression of tagged alleles residing in trans on homologous chromosomes can be revealed by double-labeling of individual histological sections. Imaging was performed by means of the intrinsic fluorescence of GFP (green) and a Cy3-conjugated secondary antibody to $\beta$-galactosidase (red).

To ensure that our imaging conditions would adequately identify double-labeled cells, a control experiment was first performed with double-heterozygous mice carrying the OMP-GFP mutation (C. Zheng, P. Feinstein, and P. Mombaerts, unpublished results) and the $B$-lac $Z$ mutation. In these mice, all mature OSNs express GFP and are green fluorescent, whereas some OSNs express also the $B$-lac $Z$ allele, resulting in red fluorescence. In double exposure, all $B$-lac $Z$ neurons appear yellow (Fig. $4 A$ ) because of the overlay of the red and green colors, demonstrating that we can detect both markers simultaneously in single cells.

In mice double-heterozygous for the $A-G F P$ and $B$-lac $Z$ mutations $(A-G F P \times B$-lacZ), double exposure reveals two differentially stained cell populations (Fig. $4 B$ ). Among 980 cells analyzed from four mice, no cell was detected expressing both markers. Likewise, analyzing 800 individual fluorescent cells from $B$-lac $Z \times C$-GFP (Fig. 4C) and $A$-lac $Z \times C$-GFP crosses (Fig. 4D), we encountered 

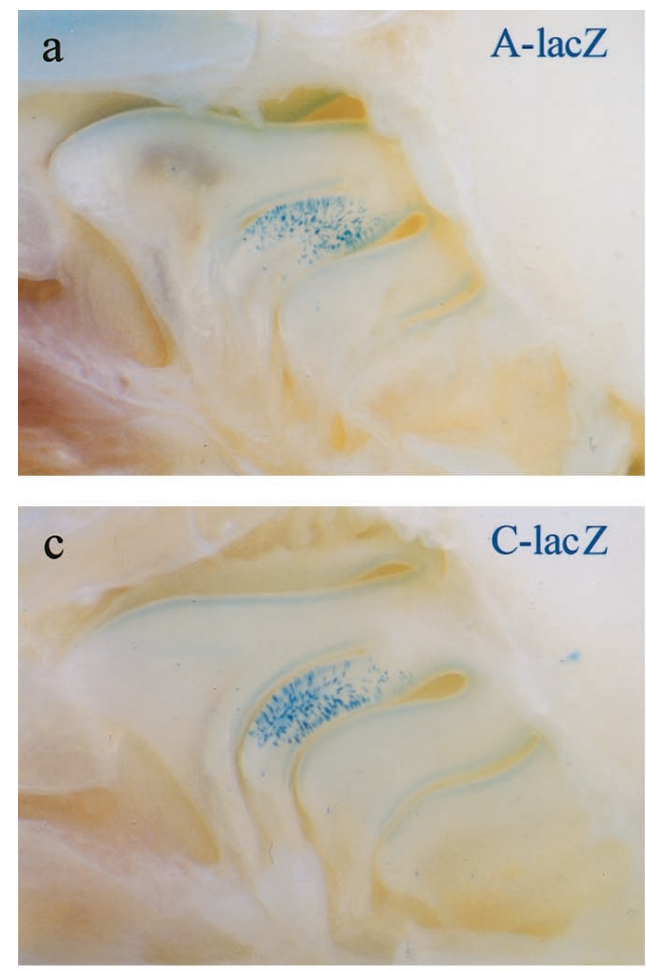

Figure 2. Patterns of $m O R 37$-expressing OSNs in the nasal cavity. $a$, Whole-mount view of the right half-head from an $A$-lacZ mouse stained with X-gal. The nasal septum was removed, allowing a view onto the medial aspect of the turbinates. Blue cells are clustered in a patch in the central region of the turbinates (anterior is to the left, and dorsal is to the top). $b$, Wholemount preparation of a $B$-lacZ mouse stained with X-gal. $c$, Whole-mount preparation of a $C$-lac $Z$ mouse stained with $\mathrm{X}$-gal. $d$, Whole-mount in situ hybridization using a probe specific for $m O R 37 B$. Reactive cells are clustered in the same small area of epithelium as those cells expressing the corresponding mutant allele in $B$-lacZ mice (compare with $b$ ). e, $f$, Adjacent coronal sections through the nasal cavity from a heterozygous $B$-lacZ mouse stained with X-gal $(e)$ or subjected to in situ hybridization with a probe specific for $m O R 37 B(f)$. The pattern of cells labeled by either X-gal staining or in situ hybridization is superimposable. Reactive cells are clustered on the tips of endoturbinates II and III and on ectoturbinate 3 . Scale bars: $e, f, 200 \mu \mathrm{m}$.

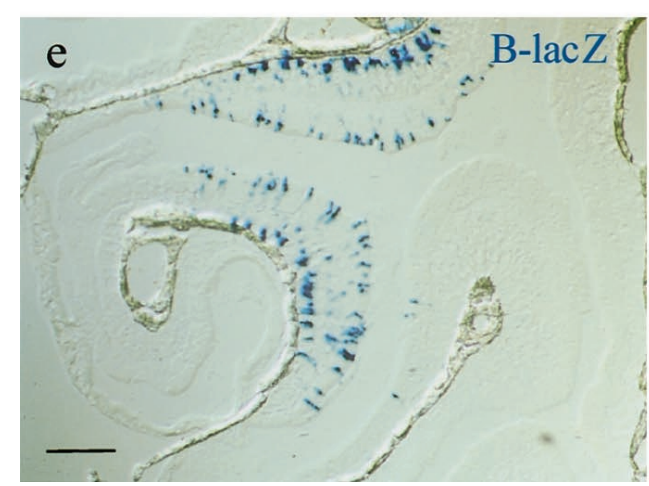

B-lacZ
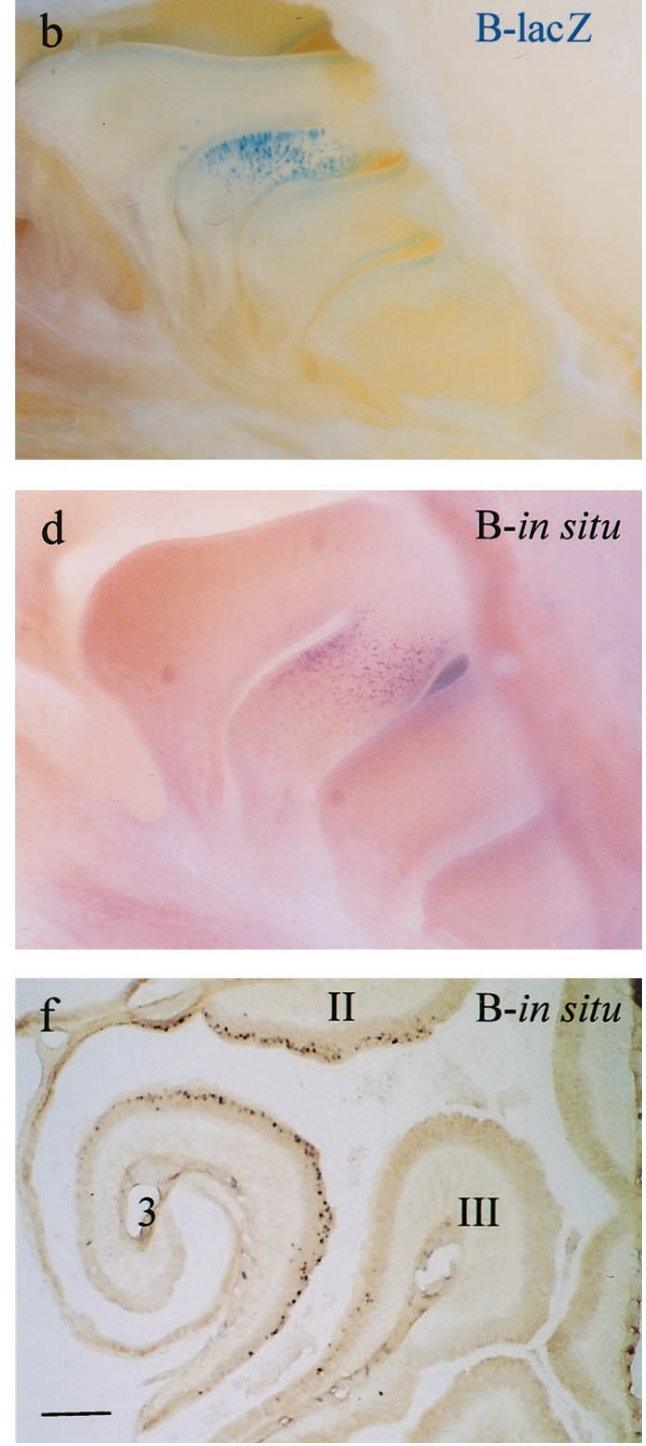

no double-fluorescent cells. Thus, coexpression of $\mathrm{mOR} 37$ genes in trans within individual OSNs is very rare, if it occurs at all.

\section{Monoallelic expression}

The mouse OR genes $I 7$ and $I 54$ are monoallelically expressed within an individual OSN, from either the paternal or maternal allele, but not both (Chess et al., 1994). It is not known whether monoallelic expression is a general feature of mouse OR genes. To image OR-specific glomeruli in the bulb using our double-labeling approach (see below), monoallelic expression of mOR37 genes must be confirmed in the gene-targeted mice; we expect that both alleles are expressed in different populations of cells and that the differentially labeled axons co-converge to the same glomeruli.

In mice compound-heterozygous for the $A$-lac $Z$ (maternal red) and $A$-GFP (paternal green) mutations, no yellow (i.e., doubleexpressing) cells are present among 750 individual cells, analyzed in randomly selected and informative sections of three mice (Fig. $4 E)$. Interestingly, red and green cells are present in equal numbers (average of $47.3 \%$ red cells and $52.7 \%$ green cells). The reverse experiment in which expression of the maternal allele results in green fluorescence and that of the paternal allele in red fluorescence gives a similar result in 750 analyzed cells (average of 51.1\% red cells and $48.9 \%$ green cells). Both alleles are thus expressed at equal frequencies in these neuronal populations. Similarly, among 800 fluorescent cells detected in four mice heterozygous for the C-lacZ (maternal) and C-GFP (paternal) mutations (Fig. $4 F$ ), no double-fluorescent neurons are detected (average of $54.2 \%$ red cells and $45.8 \%$ green cells). Thus, these $\mathrm{mOR} 37$ genes are subject to monoallelic expression at a high level of fidelity. Moreover, we have characterized this phenomenon for the first time quantitatively and at the single-cell level (Rodriguez et al., 1999).

\section{Projection patterns in the olfactory bulb}

Having shown in control experiments that the targeted mutagenesis does not alter the expression pattern of the $m O R 37$ genes, we next imaged the glomerular targets of $A$-lacZ-expressing OSNs with X-gal histochemistry in whole mounts and sections (Fig. 5).

On the ventral surface of the bulb, many blue axons converge onto a single target (Fig. $5 A$ ). This situation is in contrast with $P 2$-expressing OSNs in P2-IRES-taulacZ mice, which project their axons to at least one glomerulus located within each hemisphere of each bulb (Mombaerts et al., 1996; Wang et al., 1998; Royal and Key, 1999; Costanzo, 2000; Lin et al., 2000; Zheng et al., 2000). On serial parasagittal sections through this $A$-lac $Z$ bulb, again a single target is detectable (Fig. $5 B$ ), confirming the observation from the whole-mount preparation. The target is located on the anterior and ventral aspect of the bulb, which is facing the cribriform plate. Higher magnification and counterstaining with neutral red (Fig. 5C) identifies the stained area unambiguously as a single glomerulus.

Figure $5 D$ shows a representative section through the left and right bulbs from another mouse of this strain; on each side, a single stained glomerulus is visible located in a ventral position close to the midline of the bulb. Analysis of 30 bulbs indicates that axons of $A$-lacZ-expressing OSNs project to a defined domain of the bulb 

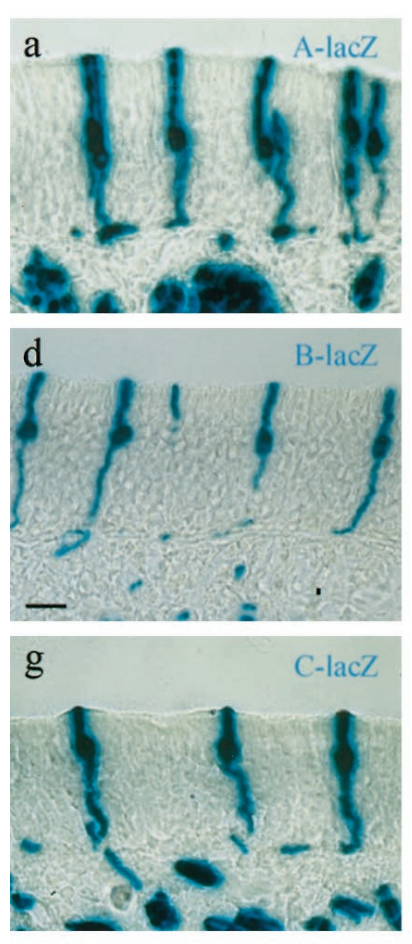
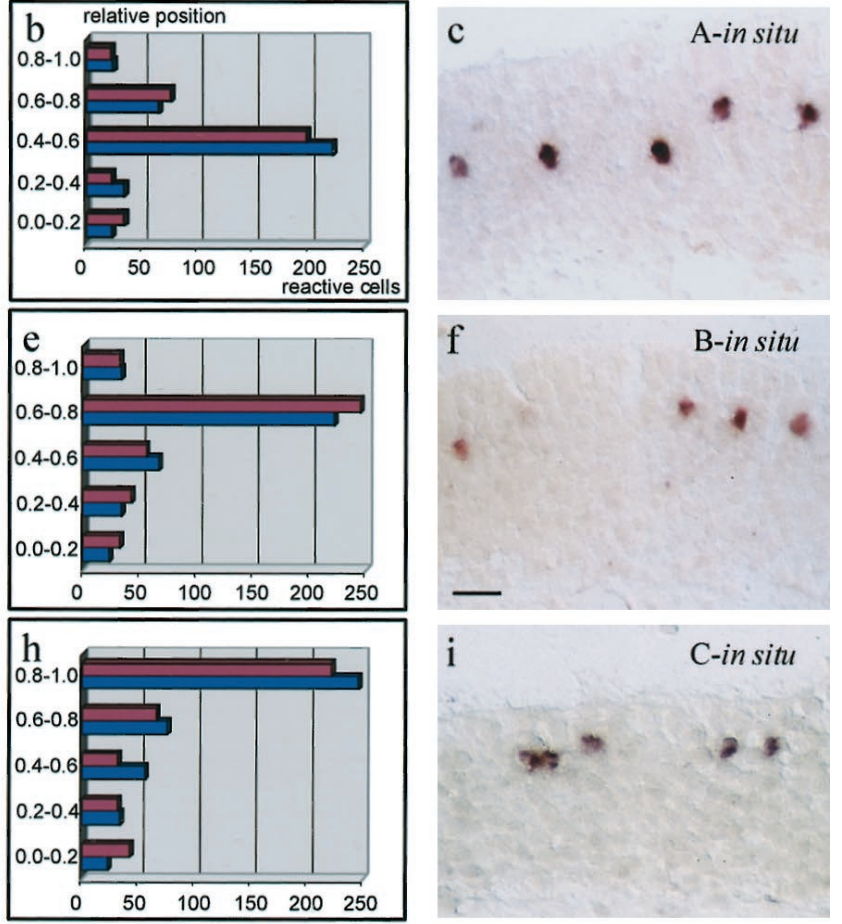
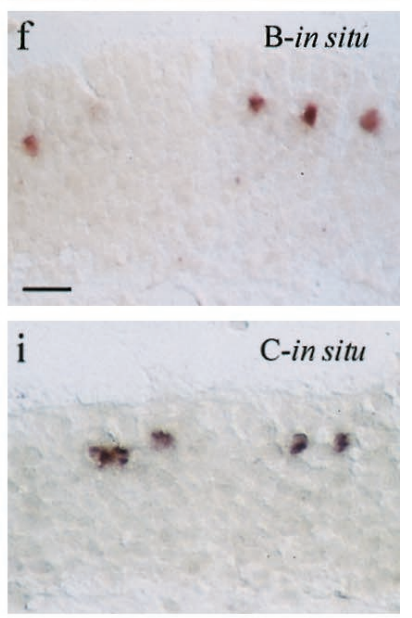

Figure 3. Laminar patterning of $m O R 37-$ expressing OSNs. $a, c, d, f, g, i$, Cross-sections of the olfactory epithelium. $b, e, h$, Graphic representations of the numbers of reactive cells in different laminae; data were collected from randomly selected and informative sections of four mice each. $a, A$-lacZ mouse stained with X-gal. Reactive cells are located within the middle layer of the epithelium. $b$, Laminar distribution of cell bodies reactive with X-gal in $A$-lac $Z$ mice (blue bars) and with a specific probe in wild-type mice (pink bars). $c$, In situ hybridization of wild-type mouse with a probe specific for $m O R 37 A$. $d, B$-lacZ mouse stained with $X$-gal. Reactive cells are closer to the luminal surface than $A$-lac $Z$ cells (see $a$ ). e, Laminar distribution of cell bodies reactive with $\mathrm{X}$-gal in $B$-lac $Z$ mice (blue bars) and with a specific probe in wild-type mice ( pink bars). $f$, In situ hybridization of wildtype mouse with a probe specific for mOR37B.g, C-lacZ mouse stained with X-gal. Reactive cells are located very close to the luminal surface. $h$, Laminar distribution of neurons reactive with $\mathrm{X}$-gal in $C$-lac $Z$ mice (blue bars) and with a specific probe in wildtype mice ( pink bars). $i$, In situ hybridization of wild-type mouse with a probe specific for $m O R 37 C$. Cells are located in an apical cellular layer, similar to $C$-lacZ-expressing neurons. Scale bars: (in $d$ ) $a, d, g, 20 \mu \mathrm{m}$; (in $f$ ) $c$, $f, i, 20 \mu \mathrm{m}$. but also reveals variability in the position of the $A$-lac $Z$ glomeruli; representative results are shown in Figure $5 D-F$. A small shift to a more medial position (Fig. $5 D$, left bulb) is found in $27 \%$ of bulbs. In $17 \%$ of the bulbs, a minor shift laterally is observed (Fig. $5 E$ ). This mediolateral shift is within the range of three glomeruli toward each side from the midline. Importantly, it is not symmetrical between the two bulbs from one individual (Fig. 5D). An additional level of variability is that a single labeled glomerulus is detected in $77 \%$ of bulbs of $A$-lac $Z$ mice and two labeled, distinct glomeruli in $23 \%$ of bulbs (Table 1). The second glomerulus is always located in close vicinity to the other one, usually 450-500 $\mu \mathrm{m}$ more posterior (Fig. $5 F$ ). This distance corresponds to more than five glomerular widths. In all five cases of bulbs with two blue glomeruli for which the contralateral bulb of the same mouse was also characterized, the other bulb had only a single blue glomerulus; in other words, the maximal number of blue glomeruli in a mouse was three.

Thus, axons of $A$-lac $Z$-expressing OSNs converge to one or two glomeruli per bulb, which are located in a defined domain but at slightly variable positions. However, a better characterization of glomerular positions involves determining the relative positions of glomeruli corresponding to various members of the mOR37 subfamily.

\section{OR-specific glomeruli}

Next we determined the glomerular targets for the other tagged mOR37-lacZ alleles (Fig. 6). The projection pattern of B-lacZexpressing neurons was analyzed in series of cross-sections through 26 bulbs of $B$-lac $Z$ mice. In $62 \%$ of bulbs, a single stained glomerulus is detected, located in the ventral region (Fig. $6 A$ ) in a position very similar to the $A$-lac $Z$ glomeruli. $B$-lac $Z$ glomeruli from different bulbs exhibit a mediolateral variability (data not shown), as was described for the $A$-lac $Z$ mice. In $38 \%$ of $B$-lac $Z$ bulbs, two stained glomeruli are observed (Table 1 ), with the second glomerulus also located in a similar ventral position of the bulb and separated from the first one by $400-500 \mu \mathrm{m}$ in the anteroposterior dimension (data not shown). From six cases with two blue glomeruli in one bulb and bilateral analysis, four had also two blue glomeruli in the other bulb.

Analysis of the third targeted allele, $C$-lacZ, yields similar observations. In $81 \%$ of 31 bulbs, a single labeled glomerulus is located in the ventral position of the bulb (Fig. $6 B$, Table 1). In the remaining $19 \%$, a second stained glomerulus is located 400-500 $\mu \mathrm{m}$ more posterior. From four cases with two blue glomeruli in one bulb and bilateral analysis, two had also two blue glomeruli in the other bulb.

Thus, OSNs expressing distinct ORs of the mOR37 subfamily project their axons to glomeruli that are located within a defined domain of the bulb (ventral and central). We estimate that this domain encompasses $\sim 30$ of the 1800 glomeruli ( $\sim 2 \%)$ in the bulb.

\section{Spatial relationships between mOR37 glomeruli}

Because the position of the labeled glomeruli varies between individuals, the identity of a glomerulus cannot be deduced from its position. It is thus conceivable that different mOR37 subpopulations project to the same glomeruli.

Therefore, mice double-heterozygous for two distinct mOR37lac $Z$ mutations were examined. This comparison is valid because mice heterozygous for a particular $m O R 37-l a c Z$ mutation are indistinguishable from homozygotes (data not shown). Figure $6 C$ shows a coronal section through the bulb of an $A$-lac $Z \times B$-lac $Z$ mouse. Two distinct glomeruli are now stained, suggesting that OSNs expressing $A$-lacZ or $B$-lacZ project to different glomeruli. Analyzing 27 bulbs from this genotype, in no case is only a single glomerulus stained (Table 1). Two and three glomeruli are detectable at similar percentages (48 and $45 \%$, respectively); only in $7 \%$, four stained glomeruli are visible in a single bulb.

Among the 13 bulbs from $A$-lac $Z \times B$-lacZ mice with two blue glomeruli, in most cases $(n=10$, or $77 \%)$ they are located side by side. Of these 10 cases, seven cases are adjacent in the mediolateral dimension (Fig. $6 C$ ), and in three cases, this relationship pertains to the anteroposterior dimension (Fig. $6 E$ ). In the three other bulbs with two labeled glomeruli, they are separated by one unlabeled glomerulus in the mediolateral dimension (Fig. 6D), or two and three unlabeled glomeruli in the mediolateral and anteroposterior dimensions, respectively (data not shown). In the 12 bulbs with three blue glomeruli, the third glomerulus is located $400-500 \mu \mathrm{m}$ more posterior, comparable with the location of the extra glomerulus observed in $m O R 37-$ lac $Z$ mice (Fig. $5 F$ ). In nine of these 12 bulbs, two glomeruli are adjacent and the third is separate; in the remaining three bulbs, none of the three labeled glomeruli are adjacent. In the two bulbs with four labeled glomeruli, a second doublet of glomeruli is present with the characteristics described 

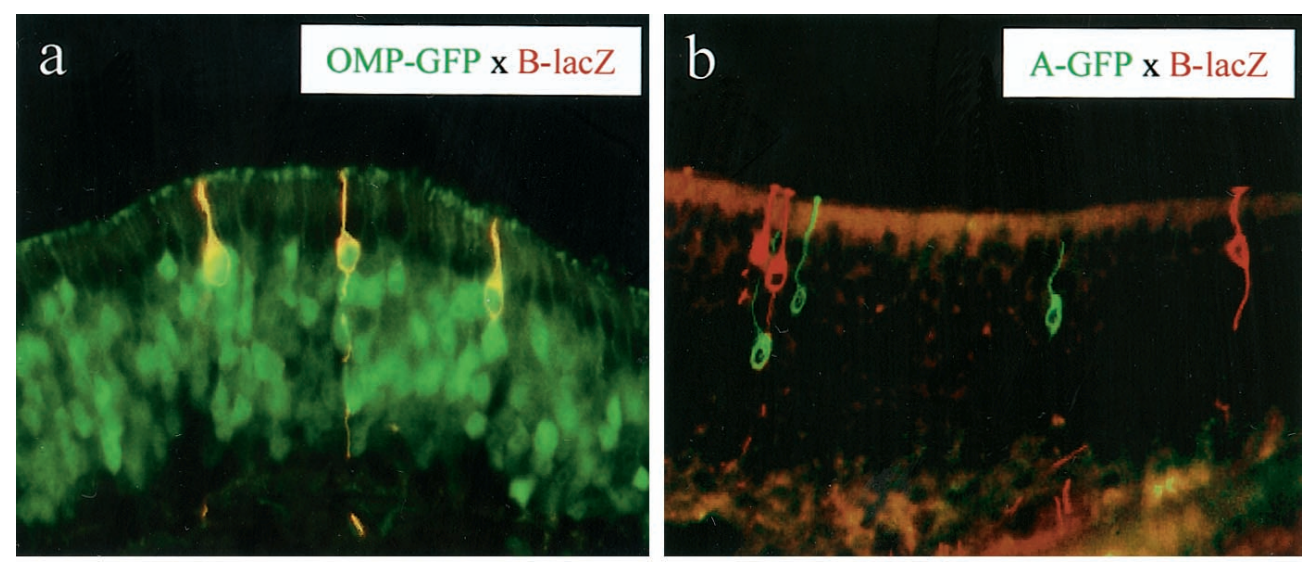

Figure 4. MOR37 gene- and allele-specific expression patterns. Cross-sections through the olfactory epithelium of double- or compound-heterozygous mice. The genotype is indicated in the top right of each panel. GFP-expressing cells are green fluorescent, lacZ-expressing cells are red fluorescent; cells coexpressing GFP and lacZ are yellow in double exposure. $a$, OMP$\mathrm{GFP} \times B$-lacZ mouse. All neurons expressing $B$-lac $Z$ coexpress GFP and are yellow. $b, A$-GFP $\times B$-lac $Z$ mouse. Two distinct neuronal populations are visible, either green fluorescent $(A-G F P)$ or red fluorescent $(B$-lac $Z)$. No double-stained neuron is detectable. $c, B$-lac $Z \times C$-GFP mouse. No cells are both red and green fluorescent. Note that both populations are located rather apically within the epithelium. $d, A$-lac $Z \times C$-GFP mouse. No double-stained neurons are detectable. Both populations are located in different horizontal layers of the epithelium. $e$, $A$-lac $\times A$-GFP mouse. The $m O R 37 A$ gene is strictly subject to monoallelic expression. Two differentially stained neuronal populations are detectable, and no double-stained cells are found. Note the location of cell bodies preferentially in the middle cellular layer of the epithelium. $f$, $C$-lac $Z \times C$-GFP mouse. The $m O R 37 C$ gene is strictly subject to monoallelic expression. Note the location of cell bodies preferentially in the apical cellular layer of the epithelium. Scale bar, $20 \mu \mathrm{m}$.
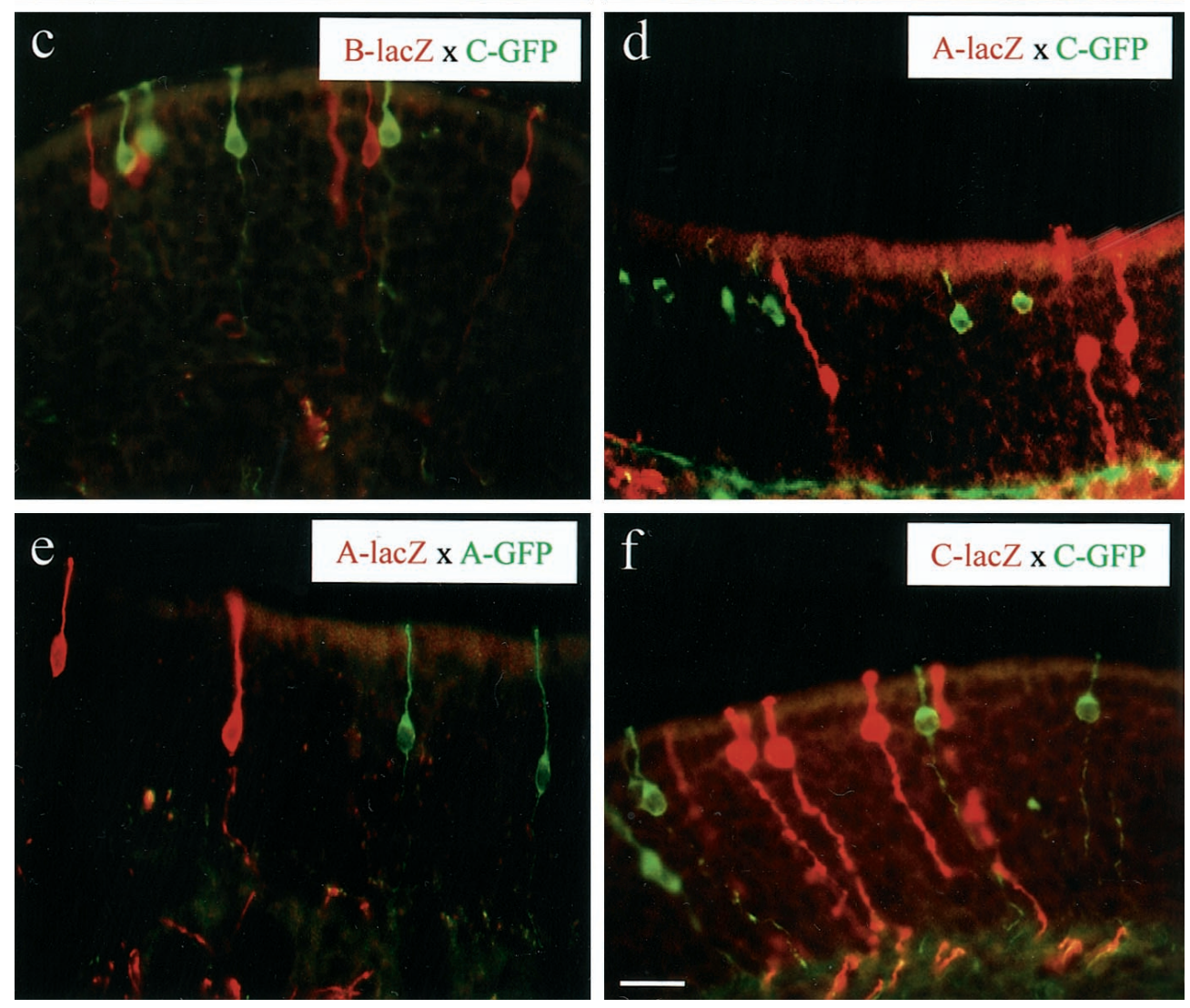

for the first pair (data not shown). Together, these observations suggest that the $A$ and $B$ glomeruli are preferentially adjacent (Table 2).

In all 29 bulbs from $B$-lac $Z \times C$-lac $Z$ mice, more than one glomerulus is stained, suggesting that $B$-lac $Z$ - or $C$-lac $Z$-expressing OSNs also project to different glomeruli (Fig. $6 F$, Table 1 ). Two or three glomeruli are identified at similar percentages (52 and $41 \%$, respectively), and four glomeruli are found in only $7 \%$ of bulbs. This distribution is comparable with that of the $A$-lac $Z \times B$-lac $Z$ genotype. A major difference, however, is that in most bulbs with two blue glomeruli (12 of 15 , or $80 \%$ ), they are not adjacent but separated by one to three unlabeled glomeruli (Fig. $6 F$ ). Similarly, in eight of 12 bulbs (67\%) with three labeled glomeruli, none of them are adjacent. In the two bulbs with four stained glomeruli, these are segregated in two pairs as described for the $A$-lac $Z \times$ $B$-lac $Z$ cross. Thus, it appears that the $B$ and $C$ glomeruli are usually separated by other glomeruli (Table 2 ).

Finally, among 31 bulbs of $A$-lac $Z \times C$-lac $Z$ double-heterozygotes, two glomeruli are stained in $65 \%$ of bulbs, three glomeruli in $32 \%$ of bulbs, and four glomeruli in a single case. As is the case in the $A$-lac $Z \times B$-lac $Z$ genotype, in most bulbs with two blue glomeruli (15 of 20 , or $75 \%$ ), they are adjacent to each other (Fig. $6 G$ ), and in only a single case of the 10 bulbs with three blue glomeruli, they are all separated. This suggests that the $A$ and $C$ glomeruli are typically adjacent (Table 2).

It is important to note that, from 35 bilaterally characterized cases of the three types of double-heterozygous $\mathrm{mOR} 37$-lac $\mathrm{Z}$ mice, most mice $(n=29,83 \%)$ have a dissimilar pattern of stained glomeruli between the left and right bulbs; this fraction is probably underestimated because glomeruli for distinct mOR37 genes cannot be distinguished, precluding their unambiguous identification on the basis of their positions.

Thus, axons from $m O R 37$-expressing OSNs project in the bulb to a defined domain in which they target distinct glomeruli at slightly variable positions. In $\sim 80 \%$ of bulbs, the $A$ and $B$ glomeruli and the $A$ and $C$ glomeruli are adjacent.

\section{TauGFP as an axonal marker}

Our analysis thus far does not permit us to distinguish to which of the two mOR37 genes each labeled glomerulus in the doubleheterozygotes corresponds. To determine unambiguously the relative spatial arrangement of particular $m O R 37$ glomeruli and to 

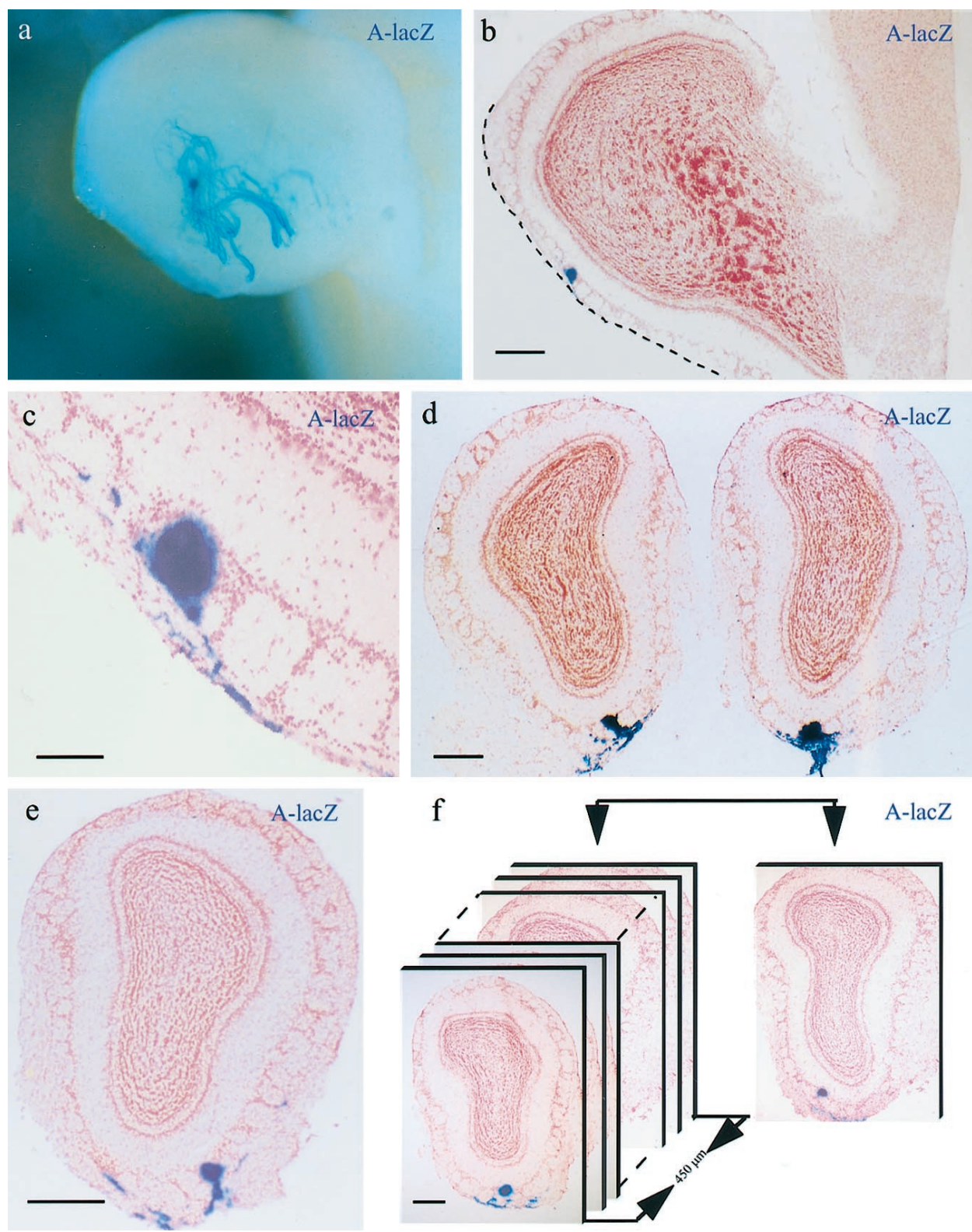

Figure 5. Glomerular pattern in A-lacZ mice. $a$, Whole-mount view onto the ventral surface of a bulb removed from the cranial cavity. Stained fibers converge on a single target (anterior is to the left, and medial is to the top). $b$, Parasagittal section through a bulb stained with X-gal and counterstained with neutral red. A single blue glomerulus is located on the anteroventral aspect of the bulb. The position of the cribriform plate is indicated by the dashed line (anterior is to the left, and dorsal is to the top). $c$, Higher magnification identifies the stained area as a single glomerulus. $d$, Coronal section through the left and right bulbs counterstained with neutral red. Individual glomeruli in the ventral and central region of the bulb are stained blue. They are located in similar positions in both bulbs (dorsal is to the top). $e$, Coronal section through the right bulb from a different A-lacZ mouse. The labeled glomerulus is positioned slightly laterally compared with $e$. $f$, Coronal sections through the right bulb. Of 40 sections, the first and last are shown. The center of the first glomerulus, as identified by $\mathrm{X}$-gal staining, is located on section 1 , the center of the second glomerulus is located on section 40 . They are separated by 34 sections without any glomerular X-gal staining. Both labeled glomeruli are located in the ventral region of the bulb but in slightly different mediolateral positions. Scale bars: $b, 400 \mu \mathrm{m}$; $c, 100 \mu \mathrm{m} ; d-f, 300 \mu \mathrm{m}$.

Table 1. Percentage of olfactory bulbs with particular numbers of stained glomeruli in mOR37-lacZ strains

\begin{tabular}{|c|c|c|c|c|c|c|}
\hline & $\begin{array}{l}\text { A-lac } Z \\
n=30\end{array}$ & $\begin{array}{l}B \text {-lac } Z \\
n=26\end{array}$ & $\begin{array}{l}C \text {-lac } Z \\
n=31\end{array}$ & $\begin{array}{l}\begin{array}{l}\text { A-lac } Z \times B \text {-lac } Z \\
n=27\end{array}\end{array}$ & $\begin{array}{l}B \text {-lac } Z \times C \text {-lac } Z \\
n=29\end{array}$ & $\begin{array}{l}\text { A-lac } Z \times C \text {-lac } Z \\
n=31\end{array}$ \\
\hline 1 Glomerulus & 77 & 62 & 81 & 0 & 0 & 0 \\
\hline 2 Glomeruli & 23 & 38 & 19 & 48 & 52 & 65 \\
\hline 3 Glomeruli & 0 & 0 & 0 & 45 & 41 & 32 \\
\hline 4 Glomeruli & 0 & 0 & 0 & 7 & 7 & 3 \\
\hline
\end{tabular}

A total of 174 bulbs were analyzed by complete serial sectioning.

show that they are innervated by OSNs expressing only one particular $m O R 37$ gene, we made use of the axonal marker tauGFP (Rodriguez et al., 1999; Zheng et al., 2000).

Figure $7 A$ shows a whole-mount preparation of a bulb from an $A-G F P$ mouse. At high magnification, a large number of strongly fluorescent fibers can be seen converging onto a distinct target. On a horizontal section through the nose and bulb of an $A$-GFP mouse, one green fluorescent target is visible in the anterior region of each bulb (Fig. $7 B$ ). The counterstaining with propidium-iodide, which highlights the shell of periglomerular cell bodies, reveals a single labeled glomerulus in each case. Thus, tauGFP is an acceptable substitute for taulacZ to image glomeruli for an $m O R 37$ gene.
It is important to demonstrate that the two populations of OSNs, each expressing a differentially tagged allele of the same mOR37 gene as a result of monoallelic expression, co-converge to the same glomeruli. Coronal sections through the bulbs from compoundheterozygous $A-G F P \times A$-lacZ mice were analyzed. Figure $7 C$ shows a triple exposure of a section counterstained with $4^{\prime}, 6$ diamidino-2-phenylindole to determine the contours of individual glomeruli. Small numbers of green fluorescent ( $A-G F P$ allele) and red fluorescent ( $A$-lacZ allele) fibers are visible in the outer nerve layer. The larger fiber bundles and the glomerulus itself appear intensely yellow because of the overlay of the two colors, indicating that the axons of both neuronal subpopulations intermingle dif- 

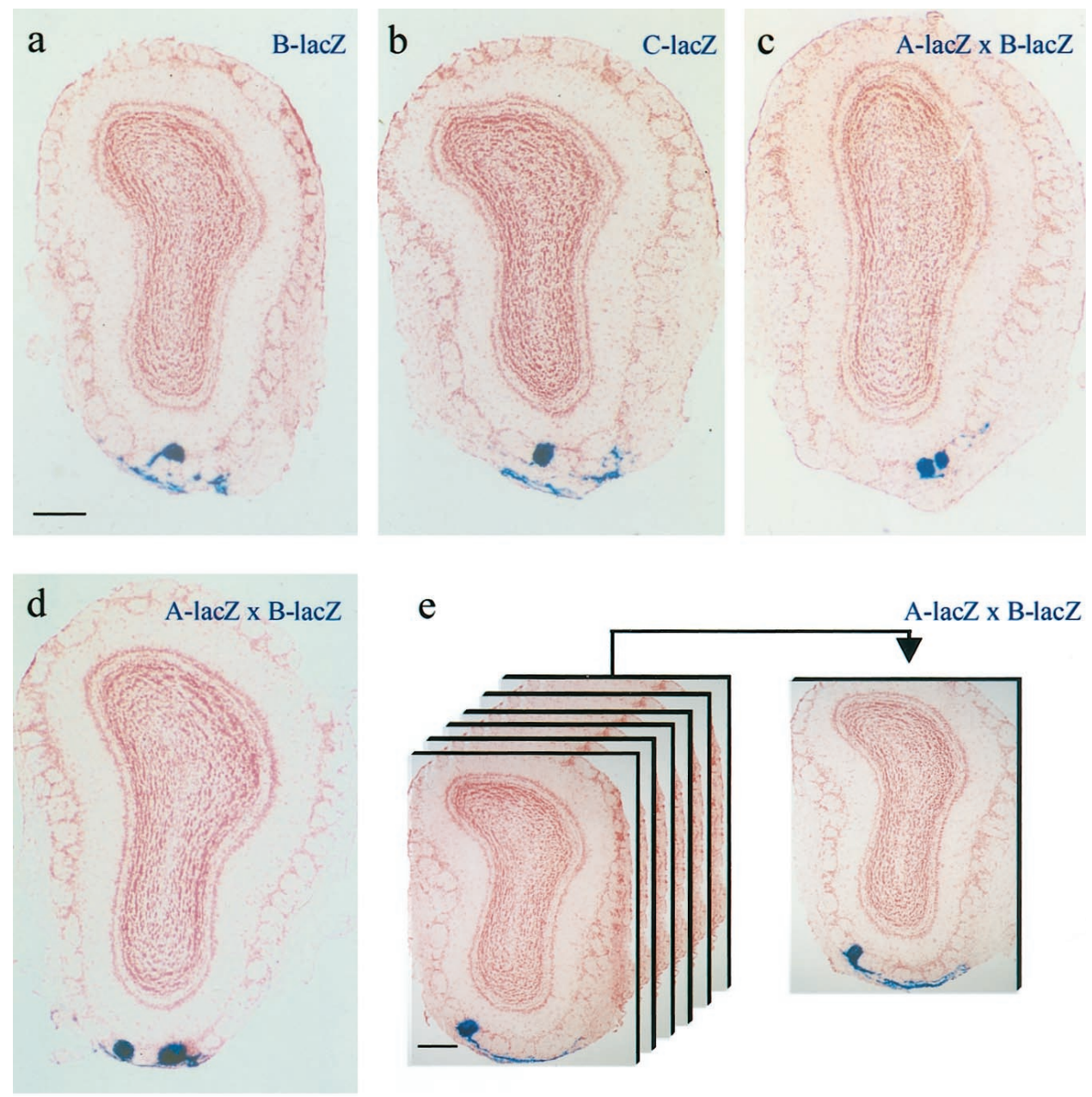

Figure 6. Glomerular patterns in mOR37lac $Z$ mice. Coronal sections through the right bulbs from various mOR37-lacZ strains stained with X-gal (dorsal is to the top, and medial is to the left ). $a, B$-lacZ. The stained glomerulus is located in the ventral and central region of the bulb. $b, C$-lacZ. The stained glomerulus is also located in the ventral and central region of the bulb. $c, A$-lac $Z \times B$-lac $Z$. Two distinct blue-stained glomeruli are visible, which are located adjacent to each other. $d, A$-lacZ $\times B$-lacZ. Two glomeruli are stained, separated in the mediolateral dimension by one unlabeled glomerulus. e, $A$-lac $Z \times$ $B$-lacZ. Of six sections, the first and the last are shown. On the first section, a stained glomerulus is visible in the ventral region of the bulb. On the next three sections, the glomerular X-gal staining disappears but reappears on the consecutive ones. Thus, these two glomeruli are located immediately adjacent to each other in the anteroposterior dimension. $f, B$-lac $Z \times C$-lac $Z$. Two glomeruli are stained, separated in the mediolateral dimension by two unlabeled glomeruli. $g, A$-lac $Z \times C$-lacZ. Two stained glomeruli are visible, located adjacent to each other in the mediolateral dimension. Scale bar: (in $a$ ) $a-d, f, g$, represents 200 $\mu \mathrm{m} ; e, 200 \mu \mathrm{m}$.
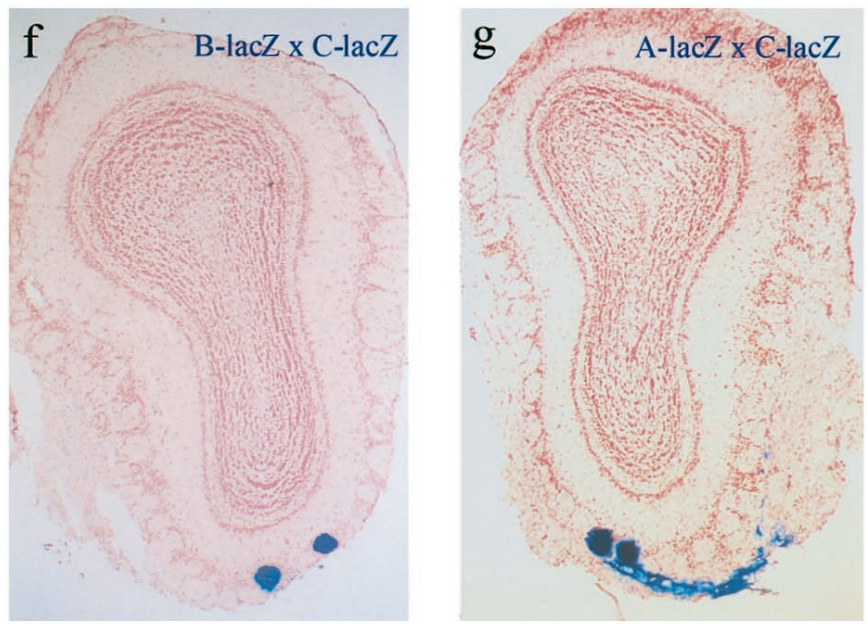

Table 2. Percentage of olfactory bulbs with adjacent and separated stained glomeruli in mOR37-lacZ double-heterozygous mice

\begin{tabular}{llll} 
& $\begin{array}{l}\text { A-lacZ } \times \text { B-lacZ } \\
n=27\end{array}$ & $\begin{array}{l}\text { B-lacZ } \\
n=29\end{array}$ & $\begin{array}{l}\text { A-lac } Z \times \text {-lacZ } \\
n=31\end{array}$ \\
\hline Adjacent & 78 & 21 & 81 \\
Separated & 22 & 79 & 19 \\
\hline
\end{tabular}

When three or four stained glomeruli are present, the bulb is scored as adjacent if two of these glomeruli are adjacent. fusely and terminate within the same glomerulus. Similar results are obtained for neurons expressing differentially tagged $m O R 37 C$ alleles (Fig. 7D). Thus, targeted integration of the IRES-taulacZ or IRES-tauGFP cassette results in identical projection patterns.

\section{Local permutations in the glomerular array}

Next, mice double-heterozygous for the $A-G F P$ and $C$-lac $Z$ mutations were analyzed to determine the position of the glomeruli relative to each other. Figure $7 E$ shows a cross-section through the bulb from an $A-G F P \times C$-lacZ mouse. The triple exposure reveals two differentially stained glomeruli. At this level of resolution, differentially labeled fibers each form distinct glomeruli, demonstrating that OSNs expressing different mOR37 genes innervate specific glomeruli. The analysis of $A$-lac $Z \times C$-lac $Z$ mice described 

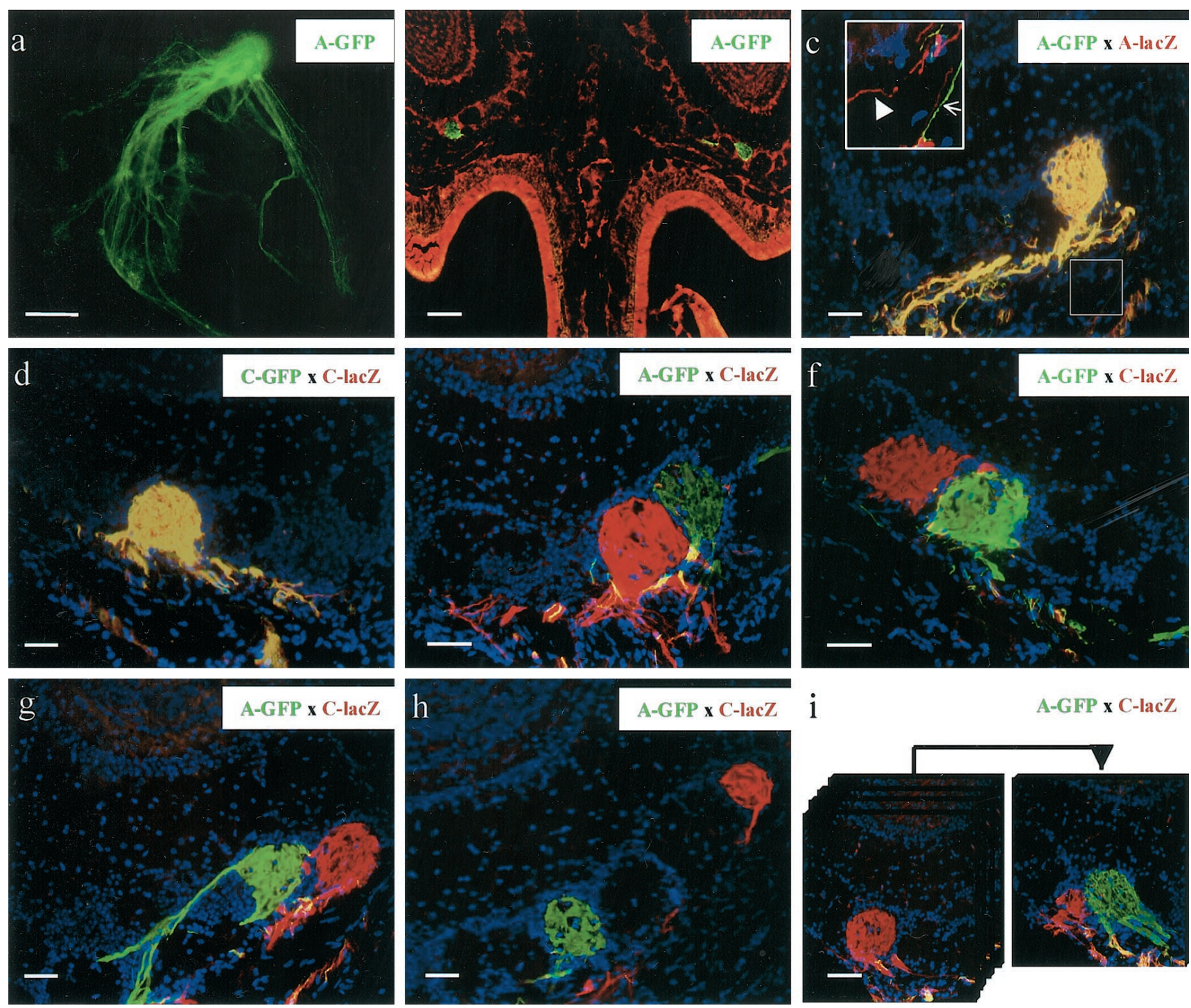

i
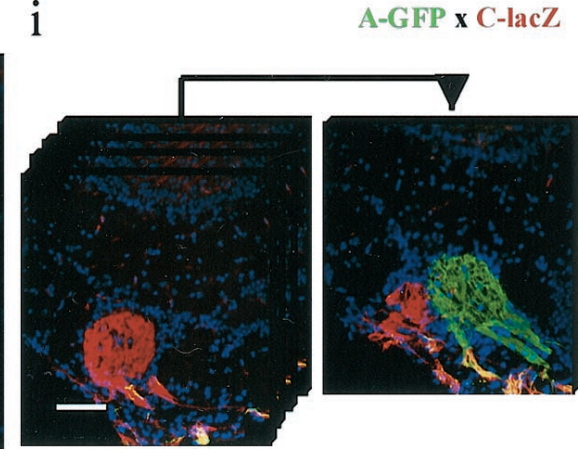

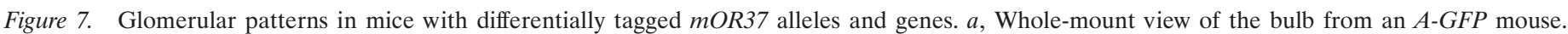

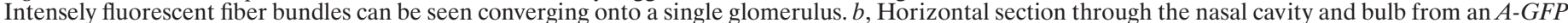

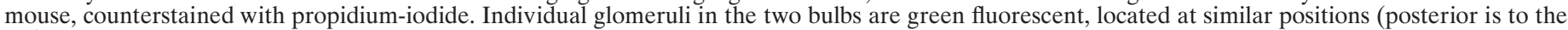

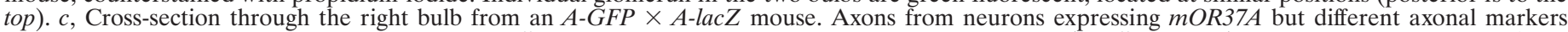

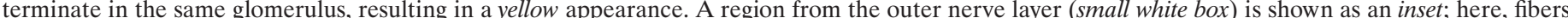

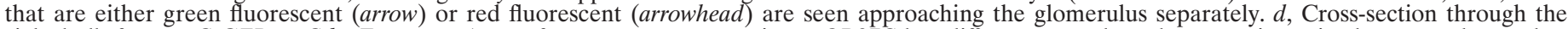

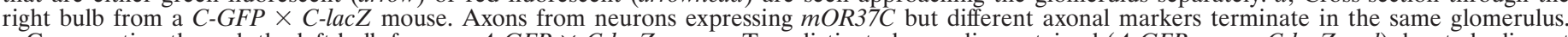

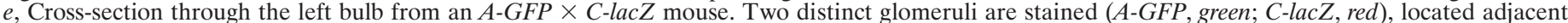

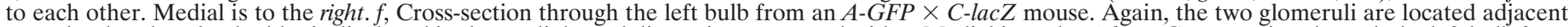

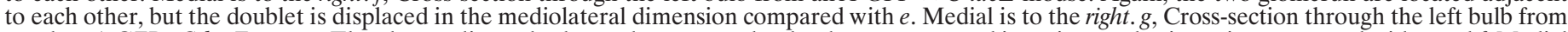

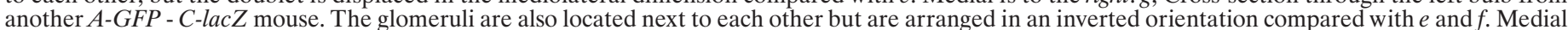

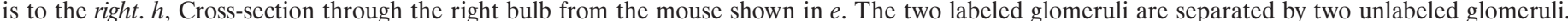

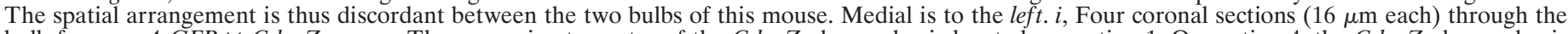

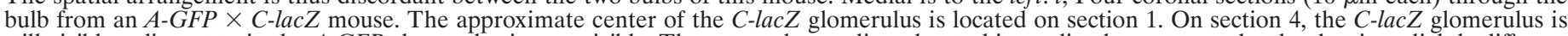

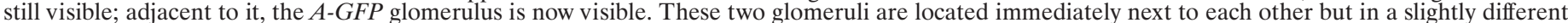
anteroposterior dimension. Scale bars: $a, 100 \mu \mathrm{m} ; b, 200 \mu \mathrm{m} ; c-i, 50 \mu \mathrm{m}$.

above suggested that the $A$ and $C$ glomeruli are usually adjacent, with 65,32 , and $3 \%$ of cases of two, three, and four glomeruli, respectively (Table 1). Among 40 bulbs of $A$-GFP $\times C$-lac $Z$ mice, there are 27 with two glomeruli, 11 with three, and two with four glomeruli; this distribution of 67,28 , and $5 \%$ matches that observed in the $A$-lac $Z \times C$-lac $Z$ cross. Similarly, in $82 \%$ of cases with two blue glomeruli, they are adjacent compared with $81 \%$ in the $A-G F P \times C$-lacZ. Thus, these observations indicate that the IREStaulac $Z$ and IRES-tauGFP alleles are functionally equivalent for our purposes and, furthermore, that the projection patterns in gene-targeted mice reflect the wild-type situation.

Because we are here able to distinguish the $A$ and $C$ glomeruli, bulbs with more than two labeled glomeruli can also be included in the analysis. Together, $A$-GFP and $C$-lac $Z$ glomeruli are adjacent in 32 of 40 bulbs $(80 \%)$ analyzed from this cross. In 19 of these 32 bulbs $(59 \%)$, they are adjacent in the mediolateral dimension. In 11 of these 32 bulbs $(34 \%)$, the $A$ glomerulus is medial to the $C$ glomerulus, as shown in Figure 7, $E$ and $F$; the position of the red-green doublet along the mediolateral axis is slightly different in these two examples, confirming the conclusion from the doublelac $Z$ cross (Fig. $6 G$ ). In eight of the 32 bulbs with adjacent glomeruli $(25 \%)$, the two types of glomeruli are arranged in the reverse, lateromedial, orientation (Fig. $7 G$ ), the $A$ glomerulus is here located lateral to the $C$ glomerulus. Two stained glomeruli are adjacent in the anteroposterior dimension in 13 of 32 bulbs (41\%). In the example shown in Figure $7 I$, the $C$ glomerulus occupies a 


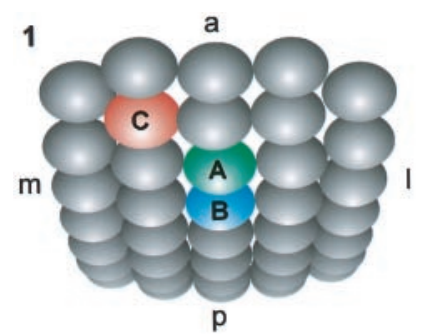

2
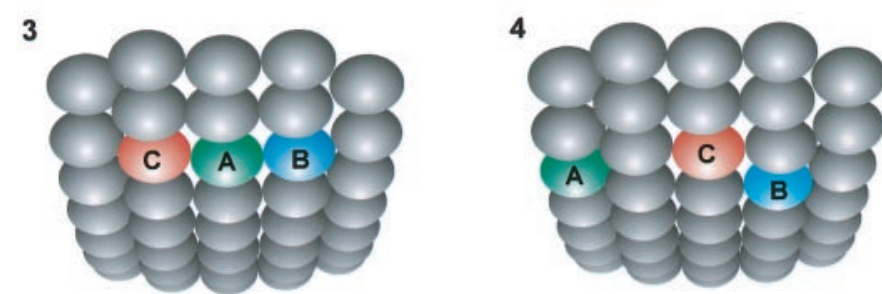

Figure 8. Local permutations in the glomerular array. Schematic threedimensional representations of a restricted domain of the glomerular array from the anteroventral region of the right olfactory bulb. This region is located behind the cribriform plate and viewed from the nasal cavity; only a small number of glomeruli is drawn. Selected arrangements of mOR37 glomeruli are depicted, with each $m O R 37$ gene corresponding to a single glomerulus for the sake of clarity and simplicity. The $A$ glomerulus is placed centrally in the three most common situations. $A, m O R 37 A ; B, m O R 37 B$; $C, \operatorname{mOR} 37 C$; $a$, anterior; $p$, posterior; $m$, medial; $l$, lateral.

position immediately anterior to the $A$ glomerulus; this arrangement is found in six bulbs $(19 \%)$; the reverse, posteroanterior, orientation is observed in the remaining seven bulbs $(22 \%)$. As is the case in $A$-lac $Z \times C$-lac $Z$ genotype, in a minority of bulbs ( 8 of 40, or $20 \%$ ), $A$ and $C$ glomeruli are separated by one, two (Fig. $7 H$ ), or three unlabeled glomeruli.

The analysis yields similar conclusions when the 27 bulbs of the $A$-GFP $\times C$-lacZ genotype with only two labeled glomeruli are considered separately. The four combinations of $A$ and $C$ glomerular relationships are $48 \%$ for mediolateral, $22 \%$ for lateromedial, $15 \%$ for anteroposterior, and $15 \%$ for posteroanterior. The variable structure of the glomerular array becomes even clearer by analysis of the patterns in the $17 A$-GFP $\times C$-lacZ mice with two bulbs characterized. Only eight mice $(47 \%)$ had the same number of glomeruli in each bulb, and a mere two mice $(12 \%)$ showed identical numbers (two) and indistinguishable relative positions (mediolateral). This is the best evidence for local permutations in the glomerular array.

\section{Variability}

From the large number of possibilities, selected combinations are shown in Figure 8 involving a single glomerulus per $m O R 37$ gene, for the sake of clarity. The quantitative analyses reveal a preferred ( $\sim 80 \%$ ) arrangement of the $A$ glomerulus adjacent to the $B$ glomerulus and the $C$ glomerulus, whereas the $B$ and the $C$ glomeruli are most frequently not located next to each other (shown in situations $1-3$ ). In the remaining $\sim 20 \%$ of cases, the $A$ glomerulus is neither located adjacent to the $B$ nor to the $C$ glomerulus (shown in situation 4). However, the $B$ and $C$ glomeruli are located adjacent to each other only in these rare cases (also shown in situation 4).

\section{DISCUSSION}

\section{Axonal projection patterns}

This study confirms and extends the concept of glomerular convergence that emerged from studies with indirect methods demonstrating that axons from some OSNs converge to individual glomeruli in mice (Ressler et al., 1993) and rats (Vassar et al., 1994) and subsequently from an alternative approach with a direct method that permits the visualization of the axonal targets of all OSNs expressing a defined OR gene, which was either P2 (Mombaerts et al., 1996) or M72 (Zheng et al., 2000). The genetic strategy is applied in this paper to three additional OR genes. Interestingly, in contrast to the two or more $P 2$ glomeruli (Mombaerts et al., 1996; Wang et al., 1998; Royal and Key, 1999; Costanzo, 2000; Lin et al., 2000; Zheng et al., 2000) or M72 glomeruli (Zheng et al., 2000) observed in each bulb, axons of mOR37 subpopulations predominantly converge to a single glomerulus in each bulb: thus, whereas at least four $P 2$ or $M 72$ glomeruli can be discerned per mouse, an mOR37 gene corresponds to at least two glomeruli per mouse. This difference may be attributed to the restricted pattern of $m O R 37$-expressing OSNs within the nasal cavity; for instance, they are not found on the olfactory epithelium that covers the nasal septum.

Although the gross features of the glomerular array are conserved, at a fine scale, the position of a specific type of glomerulus varies among bulbs of different mice. Importantly and shown here for the first time, variable interglomerular relationships are also the case among the two bulbs from one individual (Fig. 7E, $H$ ), ruling out that the genetic manipulation itself, genetic background variation, and differences in olfactory experience may underlie the local permutations. The variability in the glomerular array of the main olfactory bulb, however, is much less pronounced and at a much finer scale than in the accessory olfactory bulb in which we have not been able to discern meaningful patterns (Rodriguez et al., 1999).

Interestingly, the numbers of glomeruli for individual $\mathrm{mOR} 37$ genes show independent variations; the frequencies of bulbs from double $m O R 37-l a c Z$ mice with two stained glomeruli are equal to the products of the frequencies of bulbs with one stained glomerulus in single mOR37-lac $Z$ mice (Table 2). This finding may mean that these neuronal populations do not influence each other in a major way and that the glomerular array can locally accommodate variations in the total numbers of glomeruli.

We did not observe a correlation between the order of genes on the chromosome and the spatial patterning of glomeruli in the bulb; whereas the gene order is A-C-B, the $A$ and $C$ glomeruli, but not the $B$ and $C$ glomeruli, are usually adjacent. Furthermore, the relative order of the glomeruli does not correspond to that of the laminar patterning (A-B-C), eliminating a simple coupling between laminar distribution and glomerular position. Additionally, no obvious correlation was found between overall OR sequence similarity and glomerular positions; mOR37B and mOR37C have 93\% amino acid identity between each other, which is more than to mOR37A (87\%), yet their glomeruli are typically located the farthest from each other.

More information is required to try to correlate OR sequences, genomic locations, and glomerular positions. One study (Tsuboi et al., 1999) used the indirect method of in situ hybridization to determine the position of glomeruli for five OR genes located in two clusters. The glomeruli for OR genes of the same cluster are close to each other, with the interglomerular distances showing some variability. It must be noted that two confounding variables are present in this and our study; the OR genes are clustered and are highly homologous in sequence. It is thus not possible to distinguish whether the clustering of glomeruli within a defined domain of the bulb is the result of the genomic clustering of the OR genes or of their sequence similarity.

\section{Other species}

Although the antennal lobes of insects contain fewer glomeruli, the glomerular array also exhibits variability. The honeybee, for instance, possesses between 156 and 166 glomeruli (Flanagan and Mercer, 1989). In the fruit fly, three-dimensional reconstructions of antennal lobes resulted in the identification of 40 glomeruli according to four criteria: shape, size, position, and intensity of antibody labeling (Laissue et al., 1999). Three classes of glomeruli were distinguished: 22 "landmark" glomeruli that fulfill all four criteria, nine less well demarcated glomeruli that deviate in a single criterion, and nine poorly defined glomeruli that vary in more than one criterion. The latter two classes of glomeruli are identifiable by comparison with landmark neighbors (Laissue et al., 1999).

Zebrafish is the vertebrate species with the best characterized 
bulb (Baier and Korsching, 1994). A typical bulb contains $\sim 80$ glomeruli, of which 22 are identifiable by their characteristic position and morphology. This pattern is said to be highly stereotyped. These properties have facilitated the description of functional odor maps in the zebrafish bulb (Friedrich and Korsching, 1997, 1998).

\section{Variability in the glomerular array}

By analogy with the fruit fly (Laissue et al., 1999), glomeruli in the mouse may also fall into multiple classes. The mOR37 glomeruli may belong to the classes of less-well demarcated or poorly defined glomeruli, which may well comprise the bulk of glomeruli in the mouse because of the much larger number of glomeruli $(\sim 1800)$. Additional characterizations of P2-IRES-taulacZ mice have revealed variations in the number of $\mathrm{P} 2$ glomeruli per bulb but to various extents in different studies (Royal and Key, 1999; Costanzo, 2000; Lin et al., 2000; Zheng et al., 2000). In situ hybridization of M50 glomeruli also reveals multiple glomeruli in some cases (Lin et al., 2000). Together, these analyses rely on the absolute positions of glomeruli for a single OR. Qualitatively novel are the variations in interglomerular relationships reported here, and these findings were made possible by the pairwise analysis of two ORs with closely appositioned glomeruli. We have made similar observations for a pair of highly related OR genes, $M 71$ and $M 72$, relying on the same double-labeling approach (P. Feinstein, C. Zheng, and P. Mombaerts, unpublished observations).

Our data do not challenge the concept that the arrangement of axonal projections from the epithelium to the bulb is similar from animal to animal. What is perhaps more remarkable is not the variability described here but the highly recognizable pattern of positions of OR-specific glomeruli within the olfactory bulb. mOR37 glomeruli, for instance, are grouped within a defined domain of the bulb, which we estimate to encompass $\sim 30$ of the 2000 glomeruli, or a mere $\sim 1.5 \%$ of the surface area.

It is important to realize that the glomerular array is not distorted in a global way when bulbs are compared but is rearranged when examined in greater detail. Bulbs are not simply elongated or compressed in one or more dimensions with regard to one another, but nearest neighbor relationships between glomeruli vary qualitatively.

\section{Implications of the local permutations}

The developmental mechanisms that govern axonal convergence likely underlie the local permutations. One interpretation is that, during development, axons of OSNs expressing a given OR may project to a rather broad area of the olfactory bulb and intermingle with axons of OSNs expressing other ORs. We speculate that this broad area may occupy $\sim 1.5 \%$ of the surface area of the bulb, in accordance with the observed boundaries of the territory of mOR37 glomeruli in the adult. We further speculate that, as a result of the coalescence of neuropil into discrete glomeruli, the relative positions of the OR glomeruli may occupy virtually any position within that territory as a result of stochastic factors. It will be interesting to examine in detail the coemergence of glomeruli for two differentially tagged $m O R 37$ genes during development. Our speculations are supported by direct evidence for the coalescence of glomerular structures from a broad locus, as described recently in P2-IRES-taulacZ mice (Royal and Key, 1999).

We believe that the most important implication of the local permutations is of a practical nature. Many of the earlier methods used to describe odor maps are not performed at a scale of resolution that would be hampered by the local permutations (Buck, 1996). There is now a growing interest in single-glomerulus characterization of odorant-evoked patterns of neural activity in the olfactory bulb, such as by intrinsic signal imaging (Rubin and Katz, 1999). The compilation of a functional atlas interrelating specific glomeruli, ORs, and odorous ligands is a promising approach to olfactory coding. However, the construction of odor maps at single-glomerulus resolution could be seriously confounded by the local permutations; for instance, it should not be surprising if the observed patterns are not bilaterally symmetric. We propose that gene-targeted mouse strains of the OR-IREStauGFP design may prove useful to compensate for the problem of the local permutations. OR-specific glomeruli can be visualized in these mice by vital methods, compatible with functional imaging techniques. Other glomeruli may be characterized in relationship to the labeled glomeruli. Thus, the same genetic approach that permitted the unambiguous identification of local permutations may also provide a solution to accommodate them when building odor maps.

\section{REFERENCES}

Baier H, Korsching S (1994) Olfactory glomeruli in the zebrafish form an invariant pattern and are identifiable across animals. J Neurosci $14: 219-230$.

Buck L, Axel R (1991) A novel multigene family may encode odorant receptors: a molecular basis for odor recognition. Cell 65:175-187.

Buck LB (1996) Information coding in the vertebrate olfactory system. Annu Rev Neurosci 19:517-544.

Chess A, Simon I, Cedar H, Axel R (1994) Allelic inactivation regulates olfactory receptor gene expression. Cell 78:823-834.

Costanzo R (2000) Rewiring the olfactory bulb: changes in odor maps following recovery from nerve transection. Chem Senses 25:199-205.

Flanagan D, Mercer AR (1989) An atlas and 3-D reconstruction of the antennal lobes in the worker honey bee, Apis mellifera L. (Hymenoptera: Apidae) Int J Insect Morphol Embryol 18:145-159.

Friedrich RW, Korsching SI (1997) Combinatorial and chemotopic odorant coding in the zebrafish olfactory bulb visualized by optical imaging. Neuron 18:737-752.

Friedrich RW, Korsching SI (1998) Chemotopic, combinatorial, and noncombinatorial odorant representations in the olfactory bulb revealed using a voltage-sensitive axon tracer. J Neurosci 18:9977-9988.

Hooper ML, Hardy K, Handyside A, Hunter S, Monk M (1987) HPRTdeficient (Lesch-Nyhan) mouse embryos derived from germline colonization by cultured cells. Nature 326:292-295.

Kubick S, Strotmann J, Andreini I, Breer H (1997) Subfamily of olfactory receptors characterized by unique structural features and expression patterns. J Neurochem 69:465-475.

Laissue PP, Reiter C, Hiesinger PR, Halter S, Fischbach KF, Stocker RF (1999) Three dimensional reconstruction of the antennal lobe in Drosophila melanogaster. J Comp Neurol 405:543-552.

Lakso M, Pichel JG, Gorman JR, Sauer B, Okamoto Y, Lee E, Alt FW, Westphal H (1996) Efficient in vivo manipulation of mouse genomic sequences at the zygote stage. Proc Natl Acad Sci USA 93:5860-5865.

Lin DM, Wang F, Lowe G, Gold GH, Axel R, Ngai J, Brunet L (2000) Formation of precise connections in the olfactory bulb occurs in the absence of odorant-evoked neuronal activity. Neuron 26:69-80.

Malnic B, Hirono J, SatoT, Buck LB (1999) Combinatorial receptor codes for odors. Cell 96:713-723.

Mombaerts P (1999a) Molecular biology of odorant receptors in vertebrates. Ann Rev Neurosci 22:487-509.

Mombaerts P (1999b) Seven-transmembrane proteins as odorant and chemosensory receptors. Science 286:707-711.

Mombaerts P, Wang F, Dulac C, Chao SK, Nemes A, Mendelsohn M, Edmondson J, Axel R (1996) Visualizing an olfactory sensory map. Cell 87:675-686.

Mori K, Nagao H, Yoshihara Y (1999) The olfactory bulb: coding and processing of odor molecule information. Science 286:711-715.

Ressler KJ, Sullivan SL, Buck LB (1993) A zonal organization of odorant receptor gene expression in the olfactory epithelium. Cell 73:597-609.

Ressler KJ, Sullivan SL, Buck LB (1994) Information coding in the olfactory system: evidence for a stereotyped and highly organized epitope map in the olfactory bulb. Cell 79:1245-1255.

Rodriguez I, Feinstein P, Mombaerts P (1999) Variable patterns of axonal projections of sensory neurons in the mouse vomeronasal system. Cell 97:199-208.

Royal SJ, Key B (1999) Development of P2 olfactory glomeruli in P2internal ribosome entry site-tau-lacZ transgenic mice. J Neurosci 19:9856-9864.

Rubin BD, Katz LC (1999) Optical imaging of odorant representations in the mammalian olfactory bulb. Neuron 23:499-511.

Shepherd GM (1994) Discrimination of molecular signals by the olfactory receptor neuron. Neuron 13:771-790.

Strotmann J, Wanner I, Krieger J, Raming K, Breer H (1992) Expression of odorant receptors in spatially restricted subsets of chemosensory neurones. NeuroReport 3:1053-1056.

Strotmann J, Wanner I, Helfrich T, Beck A, Meinken C, Kubick S, Breer H 
(1994) Olfactory neurones expressing distinct odorant receptor subtypes are spatially segregated in the nasal neuroepithelium. Cell Tissue Res 276:429-438.

Strotmann J, Konzelmann S, Breer H (1996) Laminar segregation of odorant receptor expression in the olfactory epithelium. Cell Tissue Res 284:347-354.

Strotmann J, Hoppe R, Conzelmann S, Feinstein P, Mombaerts P, Breer H (1999) Small subfamily of olfactory receptor genes: structural features, expression pattern and genomic organization. Gene 236:281-291.

Tsuboi A, Yoshihara S, Yamazaki N, Kasai H, Asai-Tsuboi H, Komatsu M, Serizawa S, Ishii T, Matsuda Y, Nagawa F, Sakano H (1999) Olfactory neurons expressing closely linked and homologous odorant receptor genes tend to project their axons to neighboring glomeruli on the olfactory bulb. J Neurosci 19:8409-8418.

Vassar R, Ngai J, Axel R (1993) Spatial segregation of odorant receptor expression in the mammalian olfactory epithelium. Cell 74:309-318.

Vassar R, Chao SK, Sitcheran R, Nunez JM, Vosshall LB, Axel R (1994) Topographic organization of sensory projections to the olfactory bulb. Cell 79:981-991.

Wang F, Nemes A, Mendelsohn M, Axel R (1998) Odorant receptors govern the formation of a precise topographic map. Cell 93:47-60.

Zheng C, Feinstein P, Bozza T, Rodriguez I, Mombaerts P (2000) Peripheral olfactory projections are differentially affected in mice deficient in a cyclic nucleotide-gated channel subunit. Neuron 26:81-91. 